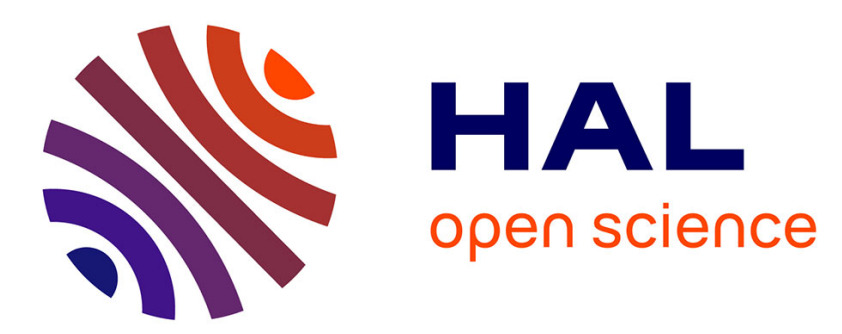

\title{
Investigation of the sensitivity of the fatigue resistance to defect position in aluminium alloys obtained by Selective laser melting using artificial defects
}

\author{
Matthieu Bonneric, Charles Brugger, Nicolas Saintier
}

\section{- To cite this version:}

Matthieu Bonneric, Charles Brugger, Nicolas Saintier. Investigation of the sensitivity of the fatigue resistance to defect position in aluminium alloys obtained by Selective laser melting using artificial defects. International Journal of Fatigue, 2020, 134, pp.105505. 10.1016/j.ijfatigue.2020.105505 . hal-02478857

\section{HAL Id: hal-02478857 \\ https://hal.science/hal-02478857}

Submitted on 14 Feb 2020

HAL is a multi-disciplinary open access archive for the deposit and dissemination of scientific research documents, whether they are published or not. The documents may come from teaching and research institutions in France or abroad, or from public or private research centers.
L'archive ouverte pluridisciplinaire HAL, est destinée au dépôt et à la diffusion de documents scientifiques de niveau recherche, publiés ou non, émanant des établissements d'enseignement et de recherche français ou étrangers, des laboratoires publics ou privés. 


\title{
Investigation of the sensitivity of the fatigue resistance to defect position in aluminium alloys obtained by Selective laser melting using artificial defects
}

\author{
Matthieu Bonneric ${ }^{\mathrm{a}, \mathrm{b}, *}$, Charles Brugger ${ }^{\mathrm{b}}$, Nicolas Saintier ${ }^{\mathrm{b}}$ \\ ${ }^{a}$ IRT Saint Exupery, B612 - 3 rue Tarfaya- CS 34436, 31405 Toulouse cedex, France \\ ${ }^{b}$ Arts et Metiers Institute of Technology, Université de Bordeaux, CNRS, INRA, INP, I2M, HESAM Université, F-33400 \\ Talence, France
}

\begin{abstract}
This study focuses on the influence of defects on the fatigue behavior of AlSi7Mg0.6 alloy produced by Selective laser melting. Artificial defects were generated in fatigue specimens by introducing holes in the CAD files prior manufacturing. The introduction of such defects, whose sizes and positions are controlled, aims to provide a proper assessment of defect sensitivity, in particular regarding the influence of defect position. Fatigue tests were performed, and finite-element calculations accounting for real defect geometries were conducted. The criticalities of the simulated defects were then evaluated using a non-local Crossland criterion, and discussed with regard to the experimental results.
\end{abstract}

Keywords:

additive manufacturing, aluminium alloys, defects, fatigue

\section{Introduction}

Over the past years, the production of Al-Si alloys by Selective laser melting (SLM) has been broadly studied, attempting to understand the relations between process parameters, microstructure, and mechanical properties [1]. Although a serious progress has been made to improve the process, the parts produced by SLM still contain defects that are impossible to eliminate, which are found to be the main cause of fatigue damage [2-4]. Therefore, studying the defect sensitivity of the fatigue resistance is an important matter for these alloys.

\footnotetext{
*Arts et Metiers Institute of Technology, Université de Bordeaux, CNRS, INRA, INP, I2M, HESAM Université, F-33400 Talence, France

Email address: matthieu.bonneric@ensam.eu (Matthieu Bonneric)
} 
The fatigue behavior of defective materials being a common issue for conventional processes, different approaches already exist in the literature to account for the presence of defects in fatigue strength prediction. It is usually assumed that the size of the largest surface or subsurface defect is the key feature that controls the fatigue strength [5]. In several works, defects are considered as initial cracks and fatigue strength is assessed from the defect sizes using a fracture mechanics framework [5-7], considering that fatigue strength is the minimum stress above which a fatigue crack is not only capable of initiating, but also of propagating over the first microstructural barriers. In particular, this method was already employed to model the fatigue strength of cast aluminium alloys [8] and of an AlSi10Mg alloy obtained by SLM [4]. However, this kind of approach presents some limitations, especially because of the so-called short crack problem for which Linear Elastic Fracture Mechanics (LEFM) is not applicable [9], and is not convenient for multiaxial conditions. Another approach consists in treating the defect as a notch, and considering the stress distributions in its neighborhood to apply a multiaxial fatigue criterion. The physical processes leading to the formation of fatigue cracks taking place within a finite volume, some works demonstrated the efficiency of considering the whole stress field within a process zone at the notch tip in order to get a proper prediction [10], instead of the local stress values at the hot spots. Such a consideration results in a modification of the local fatigue criterion, either by averaging the stresses over a physical dimension (point, length or volume) [11-13], or by the explicit introduction of the stress field gradient in the criterion [14]. It should be mentioned that such a non-local approach was successfully employed to account for the effect of the surface roughness on the High Cycle Fatigue (HCF) life of Ti-6Al-4V specimens obtained by SLM [15].

Another important feature regarding fatigue strength is the defect position with respect to the surface. Indeed, in the HCF regime, the fatigue cracks responsible for fatigue failure are usually initiated from surface or subsurface defects. This is also true for materials obtained by additive manufacturing $[4,16,17]$. For aluminium alloys, this preferential position of the critical defects can be attributed to two distinct phenomena. First, the mechanical interactions between the free surface and the defect are responsible for an increase of the local stresses compared to internal defects [18, 19]. Second, in-situ characterization of the crack propagation in cast aluminium revealed that a large part of the propagation stage is not assisted by 
the environment (air) for internal cracks, as opposed to external cracks [20,21]. Yet, it is well known that the assistance of the environment (e.g. adsorption of water vapor at the crack tip, hydrogen embrittlement) leads to a significant enhancement of the crack growth rate [22]. It results that an external fatigue crack will lead more quickly to fatigue failure than an internal crack subjected to the same loading conditions. However, despite its effect on the fatigue behavior, defect position has been much less studied than defect size, most likely because of the difficulty, from an experimental point of view, to work on defects whose sizes and positions are both controlled independently.

The aim of this study is to investigate this particular issue on an AlSi7Mg0.6 alloy obtained by SLM. To do so, artificial defects were produced by introducing holes directly into the fatigue specimen CAD files. Such a procedure allows not only for the limitation of the scattering of the experimental results, but also for the investigation of the influence of defect position independently from defect size. Fatigue tests were conducted, as well as finite element calculations accounting for real defect geometries obtained by

45 X-ray tomography. The criticalities of the simulated defects were then compared using a non local fatigue criterion, while accounting for the experimental results.

\section{Material and Methods}

\subsection{Studied material}

Samples for fatigue testing were obtained by SLM using the AlSi7Mg0.6 aluminium alloy. They were produced on a SLM 280HL powder bed machine on the additive manufacturing platform of I2M institute Futurprod, adopting the process parameters recommended by the manufacturer for Al-Si alloys (Table 1), and after drying the powders under inert environment at $150^{\circ} \mathrm{C}$ for $12 \mathrm{~h}$. After manufacturing, samples were subjected to a T6 heat-treatment, consisting in a solution treatment at $535^{\circ} \mathrm{C}$ for $2 \mathrm{~h}$, followed by a

Table 1: Process parameters recommended for Al-Si alloys

\begin{tabular}{ccccccc}
\hline $\begin{array}{c}\text { Layer } \\
\text { thickness }\end{array}$ & $\begin{array}{c}\text { Laser } \\
\text { power }\end{array}$ & $\begin{array}{c}\text { Scan } \\
\text { velocity }\end{array}$ & $\begin{array}{c}\text { Hatch } \\
\text { spacing }\end{array}$ & $\begin{array}{c}\text { Scanning } \\
\text { strategy }\end{array}$ & $\begin{array}{c}\text { Base plate } \\
\text { heating }\end{array}$ & Atmosphere \\
\hline $30 \mu \mathrm{m}$ & $350 \mathrm{~W}$ & $1650 \mathrm{~mm} / \mathrm{s}$ & $130 \mu \mathrm{m}$ & Stripes & $150{ }^{\circ} \mathrm{C}$ & Argon \\
\hline
\end{tabular}


water quenching and an artificial aging at $170^{\circ} \mathrm{C}$ for $4 \mathrm{~h}$. Figure 1 provides observations of the resulting ${ }_{55}$ microstructure. One can see elongated grains in the building direction (Figure $1 \mathrm{~b}$ ), of average size $10 \mu \mathrm{m}$ when considering transverse directions. Si precipitates were also observed on grain boundaries, as well as the complete elimination of the dendritic structure resulting from the T6 treatment. EBSD analysis was also conducted on a longitudinal section of a T6 sample. Figure 2 shows the associated orientation map as well as the inverse pole figures related to the observed area. No significant crystallographic texture was observed, possibly due to the systematic $57^{\circ}$ rotation of the scanning direction when building a new layer.

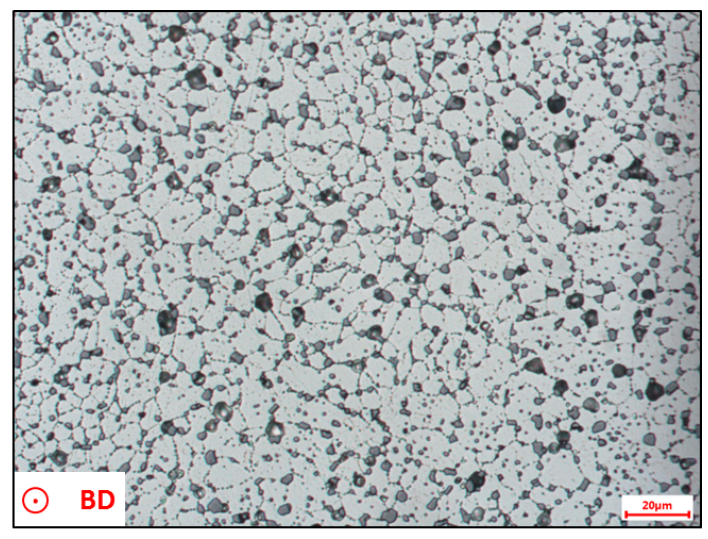

(a) Transverse section

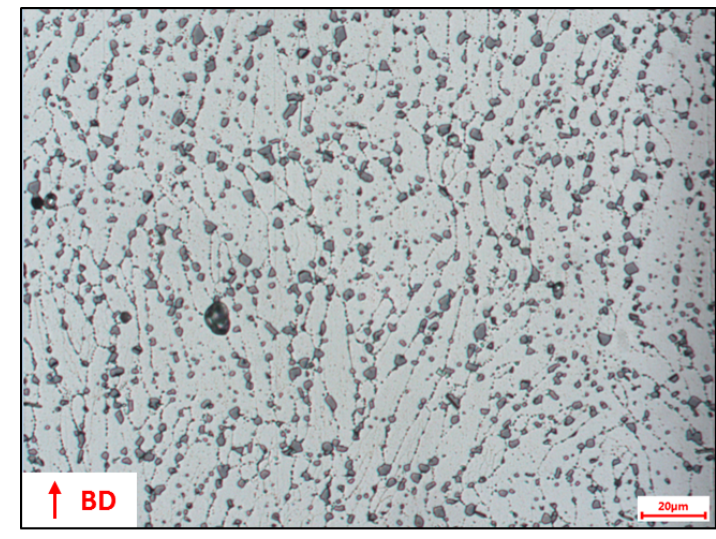

(b) Longitudinal section

Figure 1: Observations of the T6 microstructure after a chemical etching using Keller's reagent
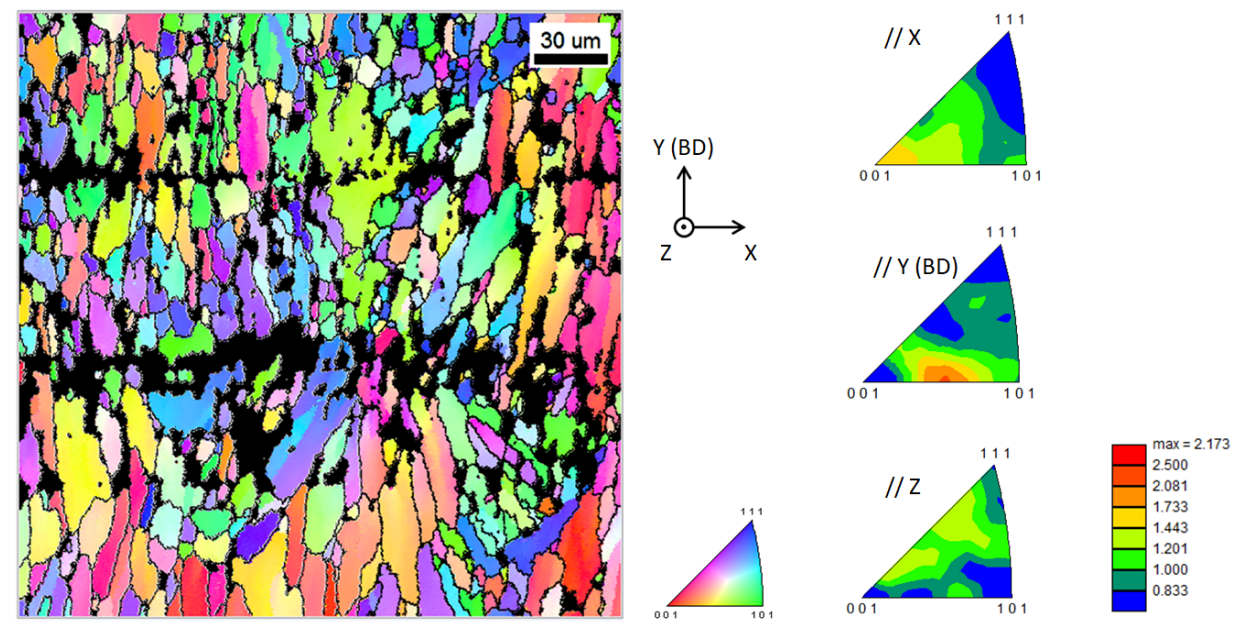

Figure 2: EBSD orientation map of a T6 sample cut in the longitudinal direction (non-indexed areas indicated colored in black) and inverse pole figures associated to the observed area. The building direction (BD) corresponds to the $\mathrm{Y}$ axis, which is also the reference direction for the orientation map. 


\subsection{Fatigue testing}

Tension/tension fatigue tests were performed on cylindrical specimens of axis parallel to the building direction, whose dimensions are given in Figure 3. Two sets of specimens were produced: the first set, denoted as NDP, consists in specimens containing only natural defects resulting from the SLM process (Natural Defect Population), whereas the second one AD corresponds to specimens with Artificial Defects. It should be noted that all the specimens were machined in order to avoid any influence of the surface roughness. HCF tests were carried out on a Zwick resonant machine with a $R=0.1$ load ratio, at room temperature in air. The stop criterion was a frequency drop of $0.5 \mathrm{~Hz}$, corresponding to a fatigue crack of approximately $1.5 \mathrm{~mm}$ in depth, or a maximum number of cycles of $2 \times 10^{6}$ cycles.

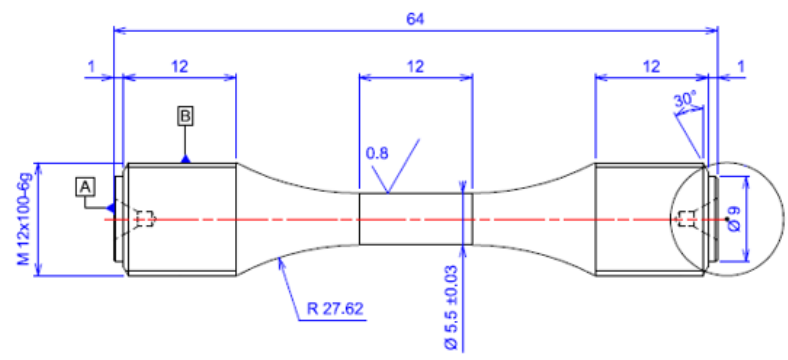

Figure 3: Geometry of the machined specimens used for $\mathrm{HCF}$ fatigue tests

\subsection{Natural Defect Population}

The gauge lengths of the NDP specimens were observed prior to fatigue testing using X-ray tomography with a voxel size of $4.7 \mu \mathrm{m}$, with the aim of characterizing the natural defect population. Central parts of three fatigue specimens were fully imaged, which represents a total data set of 268115 defects in the inspected volume $V_{0}=855 \mathrm{~mm}^{3}$. As the fatigue behavior is mostly driven by the large defect population, a peak-over threshold (POT) strategy was chosen to characterize this particular population, as proposed in [23]. To do so, only the largest defects whose size was higher than a threshold were considered, using the Murakami parameter $\sqrt{\text { area }}$ for defect size [24]. Figure 4 provides the cumulative defect size distribution so obtained from all specimens, by setting the threshold value to $65 \mu \mathrm{m}$. Please note that the threshold was arbitrarily chosen in order to have a sufficient number of defects to depict the distribution. One can see that 
defect size did not exceed $300 \mu \mathrm{m}$ in the inspected volume, and that the mean defect size was approximately $100 \mu \mathrm{m}$. It is worth noting that the latter value corresponds to ten times the grain size, which is known to be one of the most influential microstructural feature impacting on the fatigue behavior for cast Al-Si alloys $[8,20,25]$.

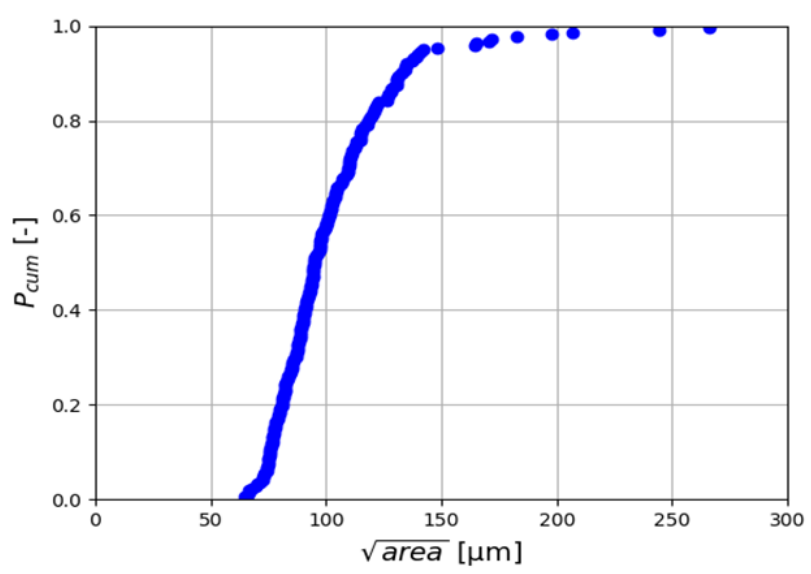

Figure 4: Cumulative size distribution of the defects of sizes $\sqrt{\text { area }} \geq 65 \mu \mathrm{m}$ obtained from X-ray tomography observations of 3 fatigue specimens

\subsection{Artificial Defects}

In order to investigate the influence of defect position, artificial defects were generated in 32 fatigue specimens. To do so, holes were directly introduced in the specimen CAD files, resulting in defects containing un-melted powder. This residual powder was supposed to have negligible influence on the mechanical properties because of the low density of the un-melted area. Two different hole geometries were considered, the first one corresponding to spherical holes of diameter $450 \mu \mathrm{m}$ (defect \#1), and the second one to ellipseshaped holes of diameter $\phi=600 \mu \mathrm{m}$ and height $h=300 \mu \mathrm{m}$ (defect \#2). Figure 5 provides CT scan views of the actual defects that are obtained when introducing such holes, compared with CAD geometries. One can see that the defect shapes are not entirely controlled and differ from CAD. However, the first attempts to generate such artificial defects, not detailed here, indicated a satisfying reproducibility in terms of size $\sqrt{\text { area }}$ with a standard deviation lower than $10 \%$, which was later confirmed in this work by the defect size measurements conducted on the fracture surfaces of AD specimens. The mean defect sizes for defects \#1 


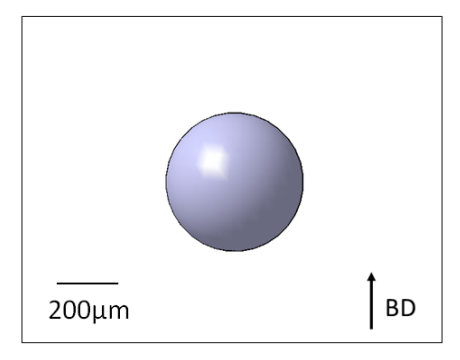

(a) CAD geometry for defect \#1

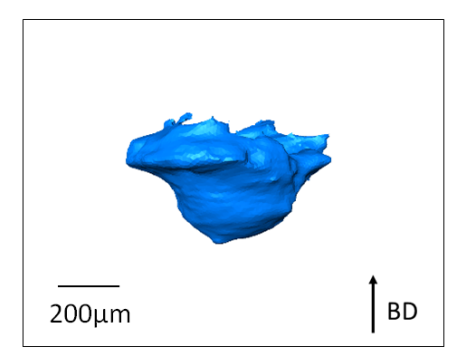

(c) Actual defect \#1

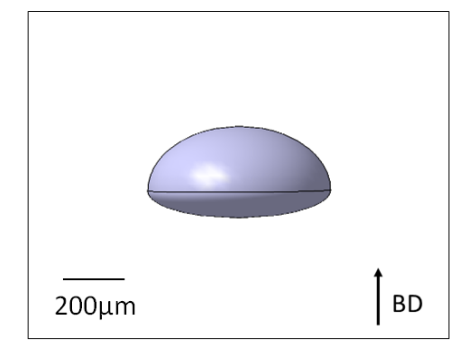

(b) CAD geometry for defect \#2

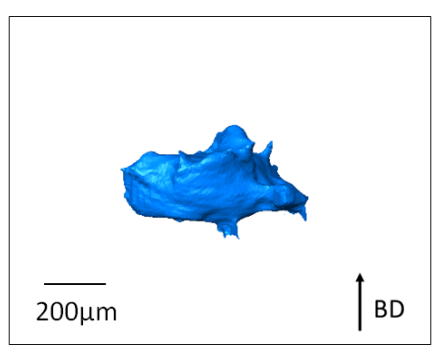

(d) Actual defect \#2

Figure 5: Comparison of the resulting artificial defects observed with X-ray tomography with the CAD geometries of the holes $(\mathrm{BD}=$ Building Direction $)$

and $\# 2$ are $\sqrt{\text { area }}=650 \mu \mathrm{m}$ and $\sqrt{\text { area }}=615 \mu \mathrm{m}$ respectively. One can note that the artificial defect sizes are in the same order of magnitude as for the largest natural defects (see Figure 4), although larger in order to enhance the development of fatigue cracks on the artificial defects instead of the natural ones.

As for the surfaces of the samples produced by SLM, the holes introduced to generate defects were subjected to a contouring strategy during manufacturing. The latter consists, for each manufacturing layer, in applying scan tracks contouring the hole with a laser power $P=300 \mathrm{~W}$ and a scan velocity $v=730 \mathrm{~mm} / \mathrm{s}$, before the bulk areas are hatched according to the parameters given in Table 1. This contouring strategy can be observed on the as-built microstructure (Figure 6), where the melt-pools related to the contour tracks pile-up from one layer to another, and are larger compared to the bulk areas. Figure 7 shows the near defect microstructure once the T6 treatment is applied. Near the defects, grains are parallel to the defect surface, instead of being aligned with the building direction, as usually observed in the hatched area (left of Figure 7a). This particular orientation was attributed to the non-melted powders inside the defect, which make heat dissipation more difficult during manufacturing compared to the melted areas. Therefore, 


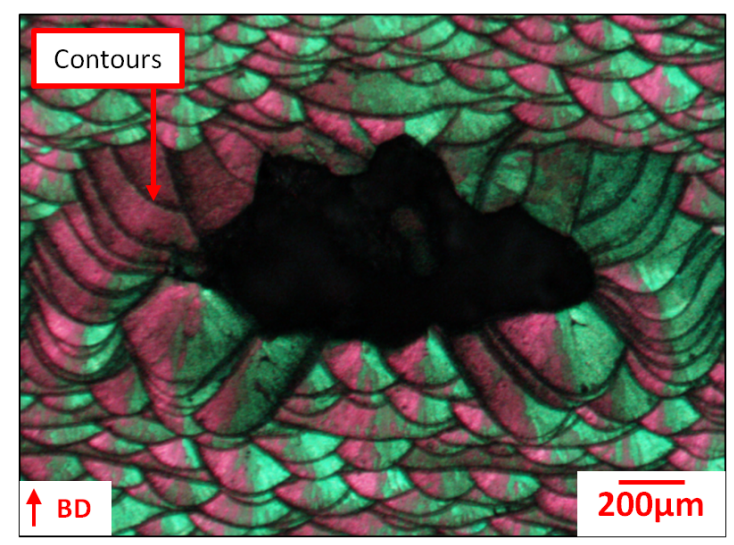

Figure 6: Optical observation using a polarizer of a longitudinal section from a sample in which an artificial defect was generated, after an electro-chemical etching using Barker's reagent

the presence of a CAD hole is responsible for a change in the cooling gradients compared to the hatched area, affecting grain orientations. One can also see that the grains near the defects, which correspond to the contour scan tracks, are slightly coarser than the ones in the bulk material, due to the use of different process parameters to scan these two areas. In addition, one should note that the piling-up of the contours, which have the same scanning direction, could also lead to the development of a crystallographic texture that might affect the first stages of development of the fatigue cracks. Nevertheless, due to the significant size of the defects compared to the characteristic length of any microstructural feature, no significant difference is expected in terms of fatigue properties between a defect in the bulk and the same defect surrounded by contours, despite the observed differences of microstructure between contours and bulk. This assumption was also supported by micro-hardness measurements (Vickers), performed in contours and bulk prior to the chemical etching on the longitudinal section shown in Figure 7. The hardness was found to be $114 \mathrm{HV} \pm 2 \mathrm{HV}$ in the bulk, and $121 \mathrm{HV} \pm 2 \mathrm{HV}$ in the contours, which is only a $6 \%$ difference. Thus, in a first approximation, it was assumed that the fatigue properties of the $\mathrm{AD}$ specimens are the same as if the defects were directly in the bulk material without any contour. Nevertheless, as the impact of the contouring strategy used for artificial defect generation on the fatigue properties has not been investigated, one should be careful when comparing the results between NDP and AD specimens.

For each defect geometry, two positions with respect to the specimen surface were considered. The batch 


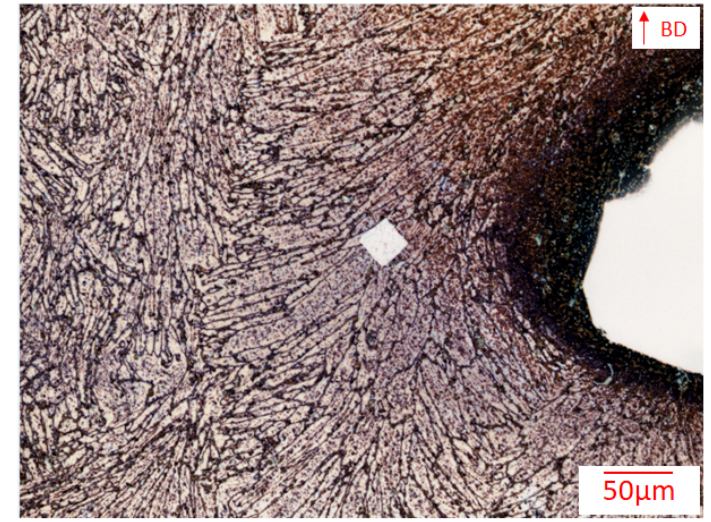

(a) Left side of the defect

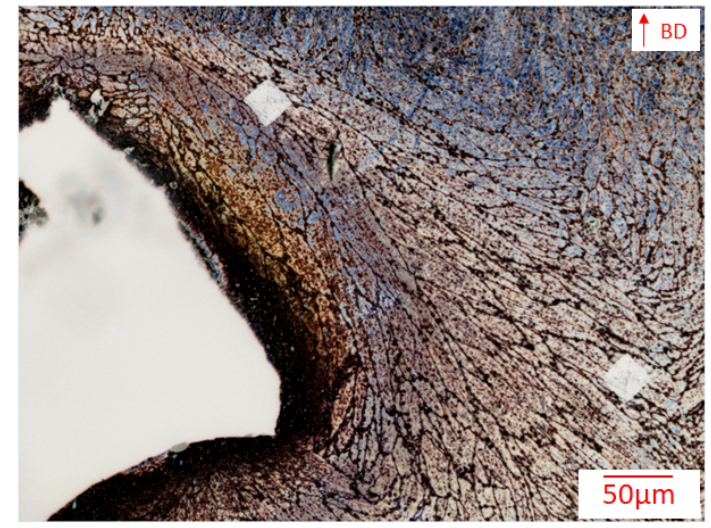

(b) Right side of the defect

Figure 7: Observation of the T6 microstructure near an artificial defect, considering a longitudinal section etched using Weck's reagent (rectangular marks correspond to micro-hardness measurements)

of $\mathrm{AD}$ specimens therefore consisted in four different sets of eight specimens. For each specimen, three repetitions of the same hole geometry were introduced in the gauge length, with all the holes positioned at the same distance from the surface. Besides, holes were spaced $3 \mathrm{~mm}$ from each other along the vertical axis of the specimen, so that defects do not interact with each other. The defect characteristics related to each set are summarized in Table 2. For sets AD-1 and AD-3, the distance $d$ between the center of the defect and the specimen surface was set to $450 \mu \mathrm{m}$ so that $\sqrt{\text { area }} / d \geq 0.8$, with the aim of generating subsurface defects according to Murakami's definition [5]. For sets AD-2 and AD-4, the distance $d$ was set to $900 \mu \mathrm{m}$ so that $\sqrt{\text { area }} / d \leq 0.8$, in order to generate internal defects.

Table 2: Characteristics of the CAD holes introduced in AD specimens

\begin{tabular}{ccccc}
\hline Set number & AD-1 & AD-2 & AD-3 & AD-4 \\
\hline Hole geometry & $\# 1$ & $\# 1$ & $\# 2$ & $\# 2$ \\
\hline $\begin{array}{c}\text { Defect size } \\
\text { area }[\mu \mathrm{m}]\end{array}$ & 650 & 650 & 615 & 615 \\
\hline $\begin{array}{c}\text { Distance to } \\
\text { the surface }[\mu \mathrm{m}]\end{array}$ & 450 & 900 & 450 & 900 \\
\hline
\end{tabular}




\subsection{Calculation settings}

Two AD specimens with subsurface defects have been observed with X-ray tomography with a voxel size of $4.7 \mu \mathrm{m}$, in order to conduct a finite element analysis accounting for real defect geometries. For each defect considered, a portion of the fatigue specimen containing the defect was meshed using the mesh of the defect surface built using CT scan data (Figure 8a and Figure 8b). Quadratic elements were used, with an element size of approximately $20 \mu \mathrm{m}$ at the level of the defect, in order to properly capture defect morphology while keeping a reasonable computational time. The meshed defects were manually positioned so that both distances and orientations with respect to the surface of the numerical specimens coincide with experimental observations (Figure 8c and Figure 8d). Other cases were also considered varying the defect position with respect to the surface to assess the influence of this parameter on defect criticality.

The elastoplastic behavior of the material was accounted for by means of an Armstrong Frederic model

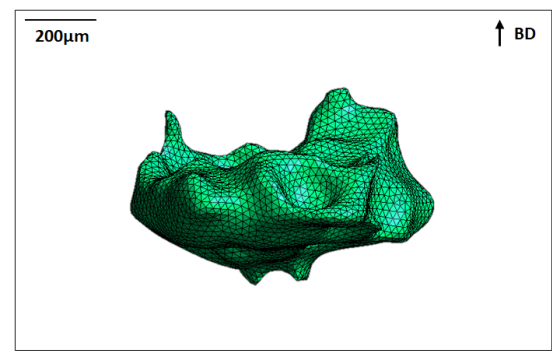

(a) Mesh of the defect surface - side view
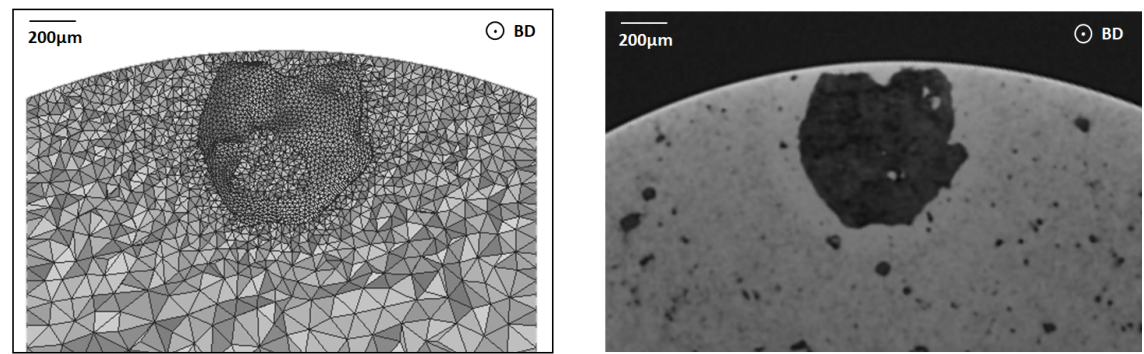

(c) Mesh of the volume containing the defect (d) CT scan observation - projection of the defect on a plane normal to the loading direction

Figure 8: Three-dimensional views of the mesh of the surface of a defect \#2, as well as the mesh of a portion of the fatigue specimen in which it was introduced, compared with X-ray observation of the real defect 
equivalent stress:

$$
f_{V M}=\sqrt{\frac{3}{2}\left(\overline{\bar{\sigma}}^{d}-\overline{\bar{X}}^{d}\right):\left(\overline{\bar{\sigma}}^{d}-\overline{\bar{X}}^{d}\right)}-R_{0}
$$

where $\overline{\bar{\sigma}}^{d}$ is the deviatoric part of the stress tensor, $\overline{\bar{X}}^{d}$ the deviatoric part of the kinematic hardening stress tensor, and $R_{0}$ an initial and constant yield stress. The evolution of the kinematic hardening respects the following condition:

$$
\dot{\overline{\bar{X}}}=C \dot{\overline{\bar{\varepsilon}}}-D \overline{\bar{X}} \dot{p}
$$

where $\overline{\overline{\varepsilon_{p}}}$ is the plastic strain tensor, $p$ the cumulative plastic strain, and $C$ and $D$ two parameters controlling strain evolution. In order to determine hardening parameters from Eq.1 and Eq.2 that describe the cyclic behavior of the material, strain-imposed tension cyclic tests were conducted. Standard machined specimens were tested on a MTS servo-hydraulic testing machine at a $f=0.1 \mathrm{~Hz}$ frequency, at two different strain amplitudes $(\varepsilon= \pm 0.3 \% ; \varepsilon= \pm 0.5 \%)$. An optimization procedure was then used to determine a set of parameters that correctly describe the experimental cycles. Table 3 summarizes all parameters used to describe the elastoplastic behavior of the material.

Table 3: Parameters used for the elastoplastic modelling of the material behavior

\begin{tabular}{cccccc}
\hline Parameter & $E[\mathrm{GPa}]$ & $\nu[-]$ & $R_{0}[\mathrm{MPa}]$ & $\mathrm{C}[\mathrm{MPa}]$ & $\mathrm{D}[-]$ \\
\hline Value & 66 & 0.33 & 215 & 83972 & 671 \\
\hline
\end{tabular}

Calculations were performed using the FE code ZEBULON, applying two cycles corresponding to an axial stress with a $R=0.1$ load ratio. The applied maximum stresses will be specified in section 3.2 for each loading case. As only uniaxial loading was considered in this study, it was judged that the choice of the fatigue criterion was not a key issue for defect criticality analysis. In a first approach, the stress-based Crossland criterion [27] was chosen for its simplicity, as well as for its low computational cost when processing the stress fields from simulations. The formulation of this criterion, provided in Eq.3, involves the amplitude of the deviatoric stress tensor second invariant $\tau_{o c t, a}$ and the maximum hydrostatic stress $J_{1, \max }$.

$$
\tau_{o c t, a}+\alpha J_{1, \max } \leq \beta
$$


In the above expression, the calculation of $\tau_{o c t, a}$ is obtained by a double maximization over the loading period:

$$
\tau_{o c t, a}=\frac{1}{2 \sqrt{2}} \max _{t_{i} \in T}\left\{\max _{t_{j} \in T} \sqrt{\left(\overline{\bar{\sigma}}^{d}\left(t_{i}\right)-\overline{\bar{\sigma}}^{d}\left(t_{j}\right)\right):\left(\overline{\bar{\sigma}}^{d}\left(t_{i}\right)-\overline{\bar{\sigma}}^{d}\left(t_{j}\right)\right)}\right\}
$$

whereas $J_{1, \max }$ is obtained as below:

$$
J_{1, \max }=\frac{1}{3} \max _{t \in T}\{\operatorname{tr}(\overline{\bar{\sigma}}(t))\}
$$

In addition, a non-local approach was used to account for the effects of stress gradients. Since it is easily applicable for complex-shaped defects, the volume-based (VB) method proposed by Taylor [11] was employed. For each Gauss point $M$, the stresses $\tau_{o c t, a}$ and $J_{1, \text { max }}$ were averaged over a volume $V_{r}$ corresponding to a sphere of radius $r$ centered on $M$. The value for parameter $r$ was set to $100 \mu \mathrm{m}$, for which a justification will be provided in 3.2.2.

To the best of the author's knowledge, the parameters $\alpha$ and $\beta$ of the Crossland criterion have not been determined in the literature for the material considered in this study. Such an evaluation is under way at the laboratory. The different simulated defects were then analyzed by comparing the distributions of the averaged stresses in a Crossland diagram $\left(\left\langle J_{1, \max }\right\rangle-\left\langle\tau_{\text {oct }, a}\right\rangle\right)$.

\section{Results and discussion}

\subsection{Fatigue tests}

\subsubsection{NDP specimens}

The maximum applied stress corresponding to the fatigue resistance at $2 \times 10^{6}$ cycles for a $R=0.1$ load ratio was assessed using the staircase method, and was found to be $\sigma_{\max , d}=152 \mathrm{MPa} \pm 8 \mathrm{MPa}$. SEM observations of the fracture surfaces indicated that the critical fatigue cracks systematically initiated from surface or subsurface defects, except for one crack initiated from an internal defect at the center of the specimen (one case among the 22 specimens observed). The critical defects mostly corresponded to lack-offusion defects or gas pores (Figure 9), although clusters of small gas pores were also found responsible for 


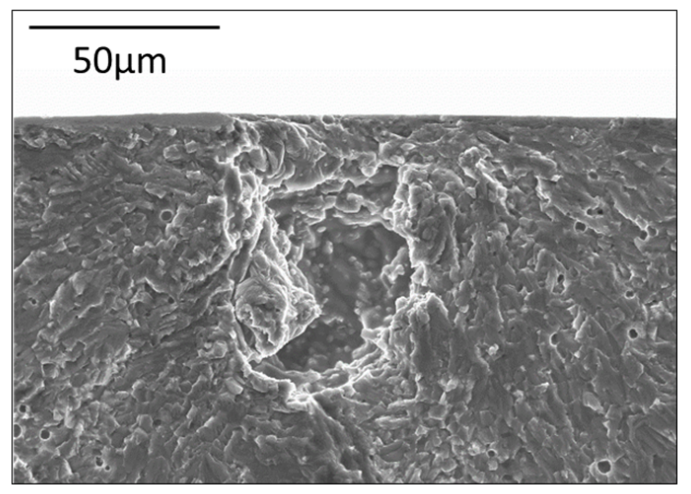

(a) Gas pore

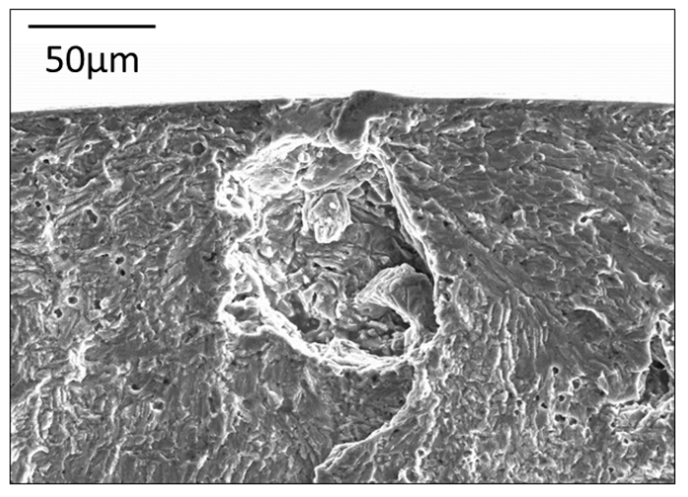

(b) Lack-of-fusion defect

Figure 9: SEM observations of typical critical defects in NDP specimens

fatigue damage in 3 cases among 22. As the latter defects were rare, and due to the inability of properly measuring their sizes, clusters were not considered in the present analysis. The sizes $\sqrt{a r e a}$ of the other critical defects were then measured, and were found to be ranging from $20 \mu \mathrm{m}$ to $117 \mu \mathrm{m}$, with a mean value of $67 \mu \mathrm{m}$. No distinction could be made between the lack-of-fusion defects and the gas pores regarding the measured sizes.

One may note that the sizes of the critical defects measured on the fracture surfaces were less than those from the largest defect population exhibited in section 2.3 considering the defects observed with X-ray tomography. This can be attributed to volume effects. Indeed, the volume inspected with tomography $\left(V_{0}=855 \mathrm{~mm}^{3}\right)$ was greater than the subsurface portion of the fatigue specimens where critical fatigue cracks are likely to initiate $\left(V=13 \mathrm{~mm}^{3}\right)$, which can be approximated by multiplying the outer surface of the gauge section by a constant depth corresponding to the average critical defect size. Note that in a general manner, the defect size distribution from CT scan data can be extrapolated accounting for volume effects to predict the size distribution of the critical defects [28]. However, a proper prediction of this distribution would require a larger CT scan volume than the one inspected in this study. This point was therefore not addressed in the present paper.

Eventually, the thicknesses of the "bridges" of material between defects and surfaces were also measured. It was found that the bridge thicknesses range from $0 \mu \mathrm{m}$ (surface defects) to $30 \mu \mathrm{m}$, with a mean value of 
$9 \mu \mathrm{m}$

\subsubsection{AD specimens}

Table 4 provides the stresses $\sigma_{\max , d}$ corresponding to the fatigue resistances at $2 \times 10^{6}$ cycles of the different AD specimens, assessed using the staircase method. For AD-1 and AD-3 specimens, which contain subsurface artificial defects \#1 and \#2 respectively, the analysis of fracture surfaces indicated that cracks successfully initiated on the artificial defects (Figure 10). For these specimens, it was therefore possible to associate the fatigue resistances with the corresponding artificial defects. For AD-2 and AD-4 specimens, which contain internal artificial defects \#1 and \#2 respectively, it was observed that the critical fatigue cracks initiated either on the artificial defects or on subsurface natural defects. More precisely, the critical defects were artificial defects in $40 \%$ of the AD-2 specimens, and in $50 \%$ of the AD- 4 specimens. Rigorously, the presence of different categories of critical defects does not allow for the association of the fatigue resistances with the artificial defects. Nevertheless, subsurface natural defects and internal artificial defects were observed approximately in the same proportions, which suggests that the fatigue resistances related to each kind of defect are similar and can be approximated by the experimental values provided in Table 4 . This assumption is also consistent with the fact that the fatigue resistances of AD-2 and AD- 4 specimens were close to that of NDP specimens.

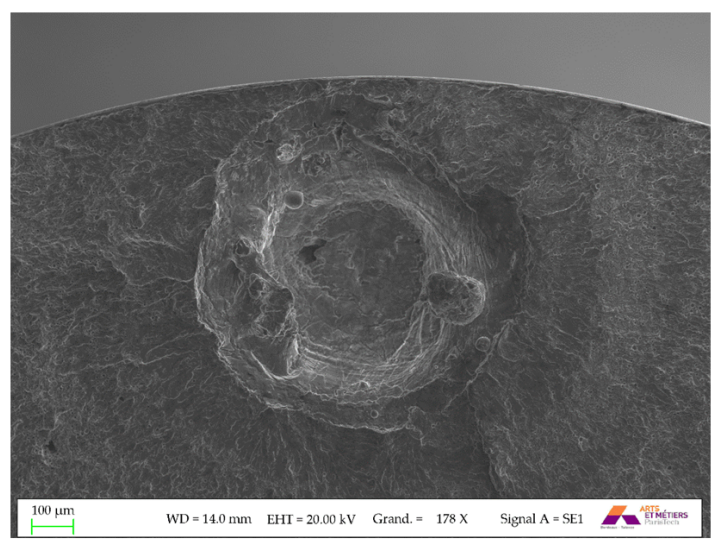

(a) Subsurface defect \#1

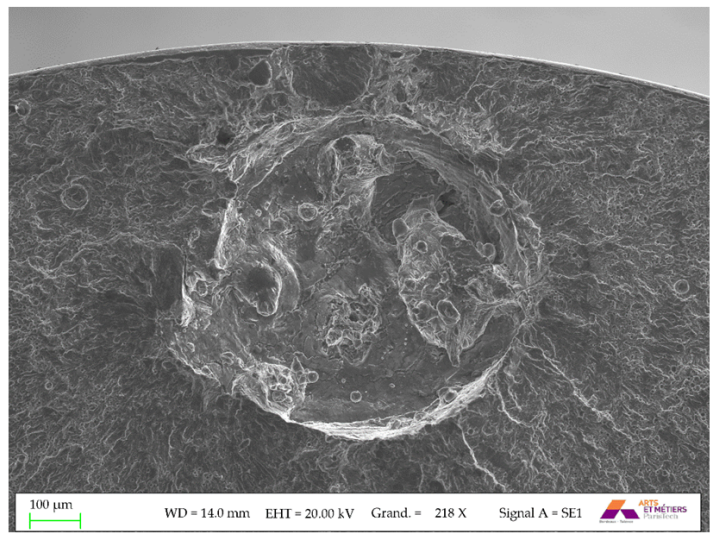

(b) Subsurface defect \#2

Figure 10: SEM observations of critical artificial defects in AD specimens 
Table 4: Fatigue resistances and characteristics of the critical artificial defects of the tested AD specimens, compared with NDP specimens. Standard deviations (SD) are also indicated.

\begin{tabular}{cccccc}
\hline Specimens & AD-1 & AD-2 & AD-3 & AD-4 & NDP \\
\hline$\sigma_{\text {max }, d}(\mathrm{MPa})$ & 107 & 145 & 127 & 151 & 152 \\
$\mathrm{SD}(\mathrm{MPa})$ & 10 & 0 & 10 & 4 & 8 \\
\hline$\sqrt{\text { area }}(\mu \mathrm{m})$ & 651 & 646 & 610 & 615 & 67 \\
$\mathrm{SD}(\mu \mathrm{m})$ & 26 & 8 & 28 & 50 & 28 \\
\hline$t(\mu \mathrm{m})$ & 44 & - & 77 & - & 9 \\
$\mathrm{SD}(\mu \mathrm{m})$ & 27 & - & 56 & - & 9 \\
\hline
\end{tabular}

Thus, the experimental fatigue resistances of $\mathrm{AD}$ specimens were associated with the corresponding artificial defects. The sizes $\sqrt{\text { area }}$ of the critical artificial defects, which were measured on the fracture increase in the fatigue resistance when defect size decreases is observed, the difference in $\sigma_{\max , d}$ between the NDP and AD specimens is not as pronounced as one could expect given the significant differences in sizes between the natural defects and artificial defects. Based on the previous analysis, one could assume that such an evolution for the fatigue resistance mostly results from the difference of position between natural defects and subsurface artificial defects (Table 4). However, one should note that the differences of morphology between the artificial defects and the natural defects could also contribute to this soft decrease of the fatigue resistance, artificial defects being larger but also less sharp than the natural ones. 


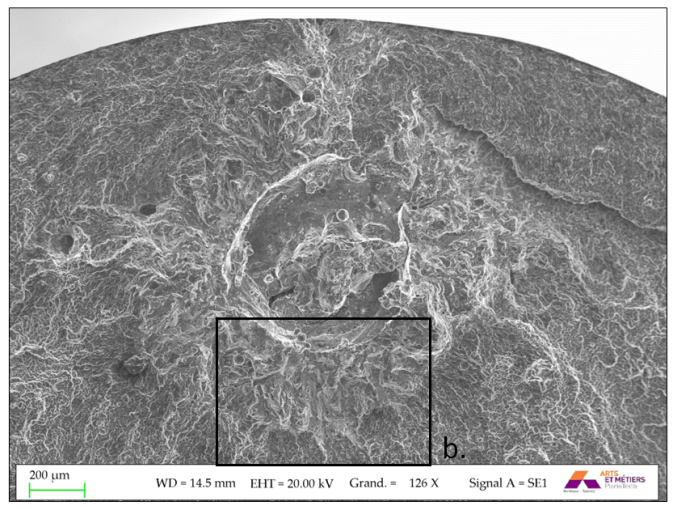

(a) Global view of the critical defects and the three dimensional propagation surface.

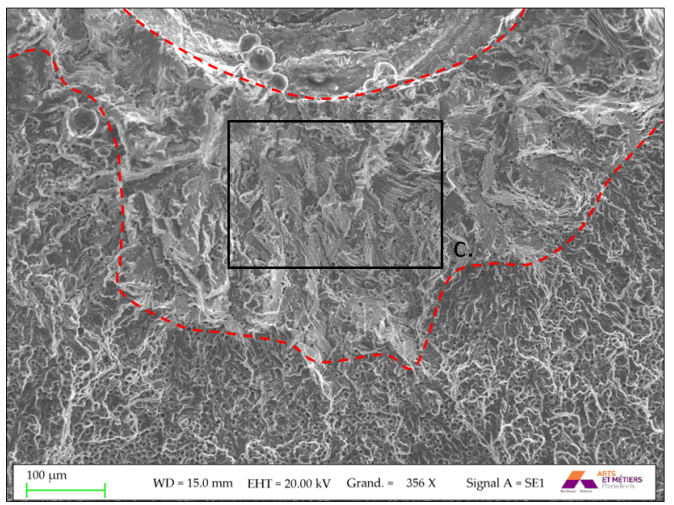

(b) Magnification on the propagation surface showing the transition between the propagation stage without the assistance of the environment (delimited by the dotted lines) and the stage with the assistance of the environment. The critical defect is on the top of the figure.

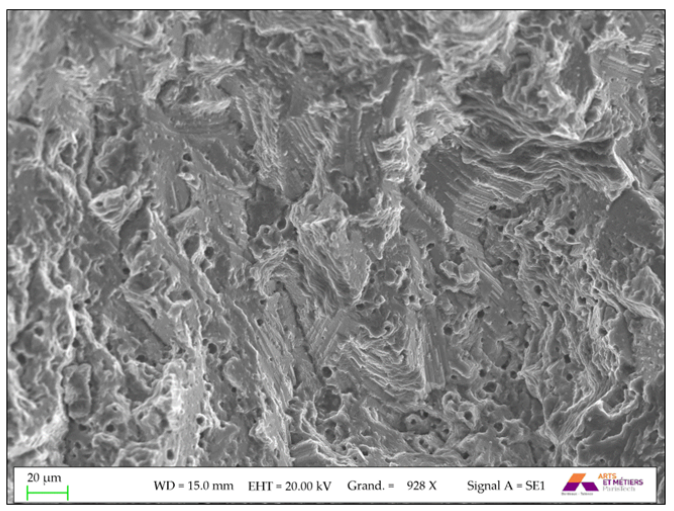

(c) Magnification on the propagation area corresponding to the stage without the assistance of the environment, showing crystallographic facets

Figure 11: SEM observations of the propagation surface of crack initiated on an internal defect \#2 
The SEM observations of the fracture surfaces also indicated differences in terms of propagation mechanisms between internal and subsurface defects. Whereas the propagation surface is plane and normal to the loading direction for subsurface defects (Figure 10), internal defects lead to more complex propagation surfaces with crystallographic facets, as shown in Figure 11. These facets are typical of a crack propagation without the assistance of the environment (ambient air), and were already observed in an earlier research work on cast aluminium [21]. It is important to highlight that such a propagation regime is usually characterized by a much lower crack growth rate than for a propagation regime assisted with the ambient air. Once the internal crack reaches the surface, propagation then becomes assisted with the environment, with the propagation surface planar and normal to the loading direction. Such transition between the two propagation regimes can be observed in Figure 11b.

\subsection{Finite element analysis}

\subsubsection{Simulated defects}

Calculations were performed following the procedure described in section 2.5. As mentioned before, two AD specimens were observed with X-ray tomography in order to use real defect geometries. The first specimen was an AD-1 specimen containing three subsurface defects \#1. During fatigue testing at $\sigma_{\max }=$ $110 \mathrm{MPa}$, a crack was detected after 2185000 cycles. The second specimen was an AD-3 specimen containing three subsurface defects $\# 2$, for which a crack was detected after 172000 cycles at $\sigma_{\max }=130 \mathrm{MPa}$. One can note that the loadings applied to Specimens 1 and 2 were very close to the fatigue resistances of AD-1 and AD-3 specimens respectively. The sizes $\sqrt{\text { area }}$ and bridge thicknesses $t$ of all artificial defects observed with X-ray tomography are provided in Table 5. For Specimen 1, the size of the critical defect was close to

Table 5: Characteristics of the subsurface artificial defects contained in the AD specimens observed with X-ray tomography

\begin{tabular}{cccc}
\hline Specimen & Defect & $\sqrt{\text { area }} \mu \mathrm{m}$ & $t \mu \mathrm{m}$ \\
\hline \multirow{3}{*}{1 (AD-1) } & 1 & 683 & 130 \\
& 2 & 668 & 40 \\
& $\mathbf{3}$ (critical) & $\mathbf{6 6 2}$ & $\mathbf{9 0}$ \\
\hline \multirow{2}{*}{2 (AD-3) } & $\mathbf{2}$ (critical) & 646 & 120 \\
& 3 & 632 & $\mathbf{3 7}$ \\
& & & 106 \\
\hline
\end{tabular}


the mean size of AD-1 critical defects provided in Table 4. However, the value of the bridge thickness for this particular defect was twice the mean value of AD-1 critical defects. Thus, the critical defect of Specimen 1 did not represent the average critical defect of AD-1 specimens regarding position. A similar observation can be made for the critical defect of Specimen 2. Indeed, whereas its size was close to the mean size of AD-3 critical defects, its bridge thickness was only half of the mean bridge thickness related to this kind of defects. One can actually note that this reduced thickness is consistent with the low fatigue life obtained for Specimen 2.

The critical defects were simulated for both Specimens 1 and 2, applying cyclic loadings corresponding to the experimental fatigue resistances of AD-1 and AD-3 specimens respectively. They will be designated as "Critical defects" in what follows. Other calculations were also performed positioning these defects farther from the surface as for the internal artificial defects in AD-2 and AD- 4 specimens. For such cases, the applied cyclic loadings corresponded to the experimental fatigue resistances related to the internal defects. Besides, since the critical defects of Specimens 1 and 2 did not represent the average critical defects of AD-1 and AD-3 specimens in term of position, other subsurface defects from Specimens 1 and 2 were considered. The defect 2 of Specimen 1 was chosen to be simulated, as both its size and position were close to those of the average AD-1 critical defect. The defect 3 of Specimen 2 was chosen for the same reasons. These two defects will be designated as "Average defects" in what follows.

\subsubsection{Gradient effect consideration}

The use of a volume-based method to apply a non-local Crossland criterion usually requires to pay a particular attention to the size of the process zone in which stresses are averaged. In the present case, this process zone is the sphere $V_{r}$ of radius $r$ defined in section 2.5. Due to significant stress gradients in the defect vicinity, the choice of the $r$ value has a significant influence on the averaged stresses $\left\langle J_{1, \max }\right\rangle$ and $\left\langle\tau_{o c t, a}\right\rangle$, as it can be seen in Figure 12a. In order to evaluate the near-defect area affected by stress gradients, different stress profiles from both defects \#1 and \#2, were considered (Figure 12b). They all describe the evolution of the Von Mises equivalent stress $\sigma_{V M}$ normalized by the applied nominal maximum stress $\sigma_{n o m}$ with the distance to the edge of the defect in a plane normal to the loading direction $d$. One can see that the 
different profiles follow the same trend, and that the gradient is almost stabilized from $d=100 \mu \mathrm{m}$. Thus,

the $r$ value was set to $100 \mu \mathrm{m}$ to capture gradient effects in what follows. One should note that this value is in the same order of magnitude as the El-Haddad parameter $a_{0}=75 \mu \mathrm{m}$ determined in the literature for as-built AlSi10Mg alloy [4].

\subsubsection{Influence of defect position on the stress distributions}

Simulations were performed to evaluate the influence of defect position on the averaged stresses $\left\langle J_{1, \max }\right\rangle$ and $\left\langle\tau_{o c t, a}\right\rangle$. To do so, the geometry of the critical defect \#1 was used, varying the distance $d$ between the center of the defect and the specimen surface in each simulation. In particular, a subsurface defect with a thin bridge of material of thickness $t=30 \mu \mathrm{m}$ was considered $(d=410 \mu \mathrm{m})$, to be compared to Critical defect \#1 $(d=470 \mu \mathrm{m}$ and $t=90 \mu \mathrm{m})$. An internal defect corresponding to AD-2 specimens was also simulated $(d=900 \mu \mathrm{m})$, as well as a defect centered in the middle of the fatigue specimen $(d=2750 \mu \mathrm{m})$. The same cyclic loading was applied in all simulations, corresponding to the experimental fatigue resistance of subsurface artificial defects \#1, so that defect position was the only varying parameter. Figure 13 shows the obtained stress distributions represented in the Crossland diagram. Both the shear stress amplitude $\left\langle\tau_{o c t, a}\right\rangle$ and maximum hydrostatic stress $\left\langle J_{1, \max }\right\rangle$ are increased when the distance $d$ decreases. Thus, the smaller $d$
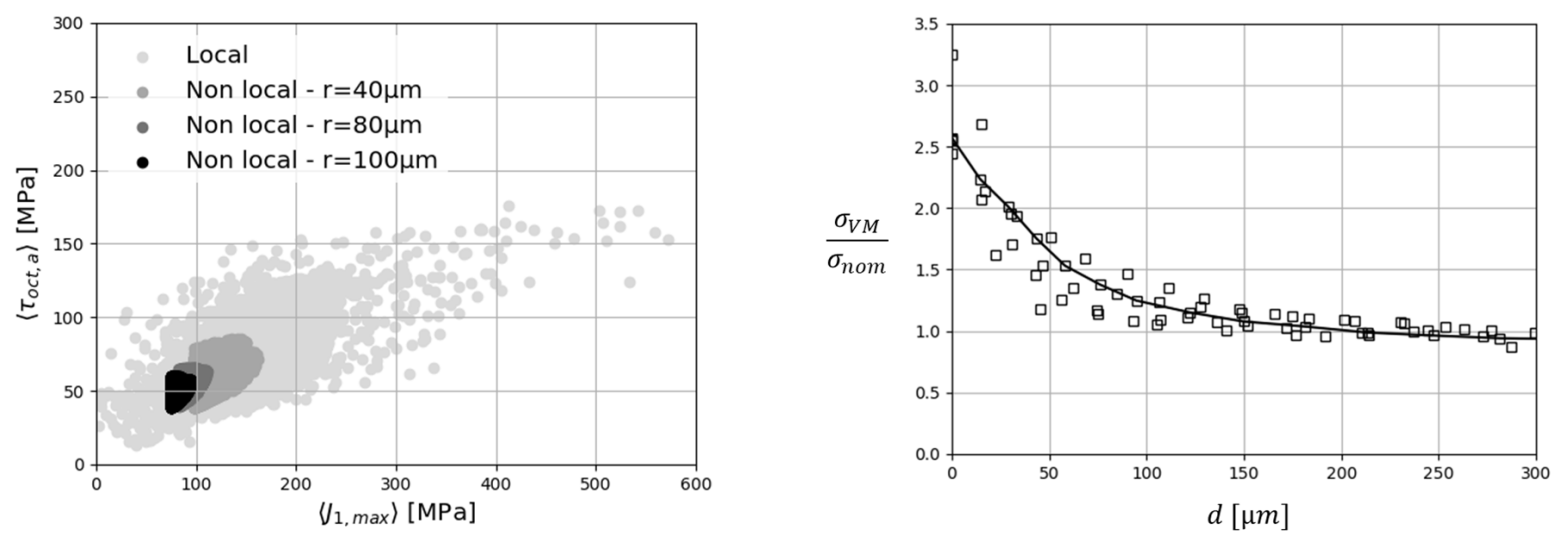

(a) Averaged stress distributions related to Critical defect \#1(b) Von Mises equivalent stress $\sigma_{V M}$ normalized by the nominal represented in a Crossland diagram for different $r$ values maximum stress $\sigma_{n o m}$ as a function of the distance to the edge of the defect $d$ for both Critical defects \#1 and \#2

Figure 12: Influence of the stress gradients on the averaged stress distributions 
is, the more the criticality of the defect is important. In particular, it is interesting to note the difference between the internal defect corresponding to AD-2 specimens and the centered defect, which points out that the criticality of internal defects (as defined by Murakami [5]) regarding crack initiation still depends on defect position. This result therefore shows that a simple discrimination between internal defects and subsurface defects in the sense of Murakami is not enough to account for the effect of position on the defect criticality regarding crack initiation.

One can also see that the variations in term of shear stress $\left\langle\tau_{o c t, a}\right\rangle$ are more important for subsurface defects compared to the internal ones, due to high shear stress values for subsurface defects. This is clearly visible when considering the defect with a thin bridge of material $(d=410 \mu \mathrm{m})$. As one can see in Figure 14, these high shear stress values are associated to the bridge between the defect and the surface. They result not only from the interactions between the defect and the free surface, which are known to be responsible for an increase of the local shear stresses, but also from a reduction of the process zone in which stresses are averaged. Indeed, it is important to note that the effective volume in which stresses are averaged is restricted to the material points, and may then be smaller than the volume of the sphere $V_{r}$, especially in the bridge. It results in high averaged stresses for defects having thin bridges. Thus, the VB method

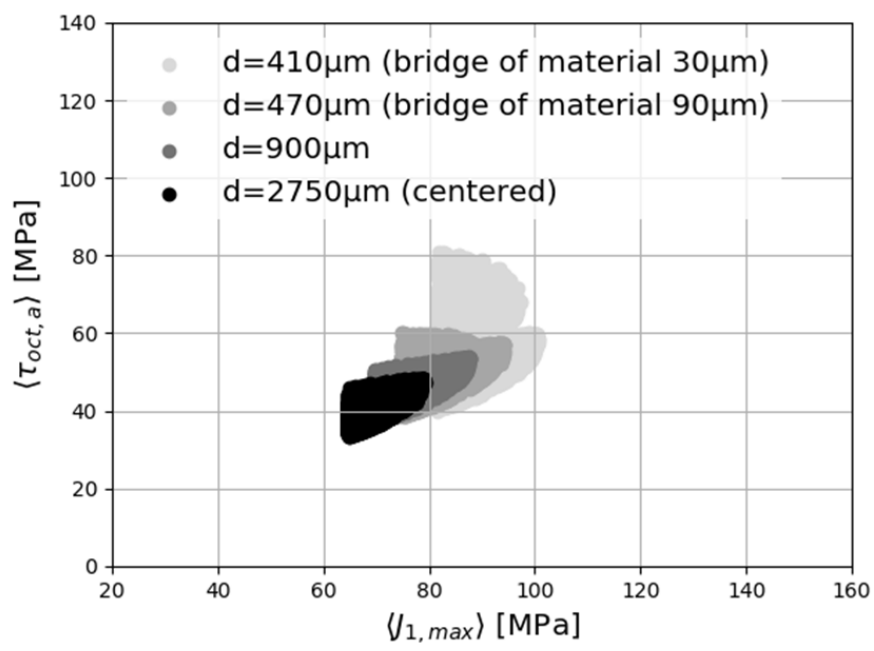

Figure 13: Comparison of the averaged stress distributions obtained when varying the position of defect \#1 $(\sqrt{a r e a}=662 \mu \mathrm{m})$ and applying a cyclic loading corresponding to the experimental fatigue resistance of subsurface artificial defects \#1 
intrinsically accounts for the physical limitation of the volume in which the fatigue damage processes take place in the bridge area.

\subsubsection{Comparison of defect criticalities}

This last section aims to confront different simulation results accounting for the experimental results obtained in section 3.1. To do so, subsurface and internal defects were simulated for both defects \#1 and \#2, applying for each kind of defect the cyclic loading that reproduces the experimental fatigue resistance of the corresponding AD specimens. In addition, for subsurface defects, both the Critical and Average defects presented in section 3.2.1 were simulated. In order to easily compare defect criticalities, a line of equation $\left\langle\tau_{\text {oct }, a}\right\rangle+A\left\langle J_{1, \max }\right\rangle=B$ was drawn on each of the Crossland diagrams presented hereafter. The value for $A$, which defines the slope of this line, corresponds to the Crossland parameter $\alpha$ identified at $5 \times 10^{6}$ cycles for a defect-free cast T6 AlSi7Mg0.6 alloy $[29,30]$. The value for $B$ was adjusted for each diagram, so that $B \approx \max _{i \in N}\left\{\left\langle\tau_{o c t, a}\right\rangle(i)+A\left\langle J_{1, \max }\right\rangle(i)\right\}$, where $N$ is the set of Gauss points related to all defects to be compared. Thus, assuming that the value of the parameter $A$ is close to the Crossland parameter $\alpha$ of the present material, the line slightly intersects the distribution of the most critical defect.

Figure 15a shows the comparison of the stress distributions associated to the Average defect \#1 and

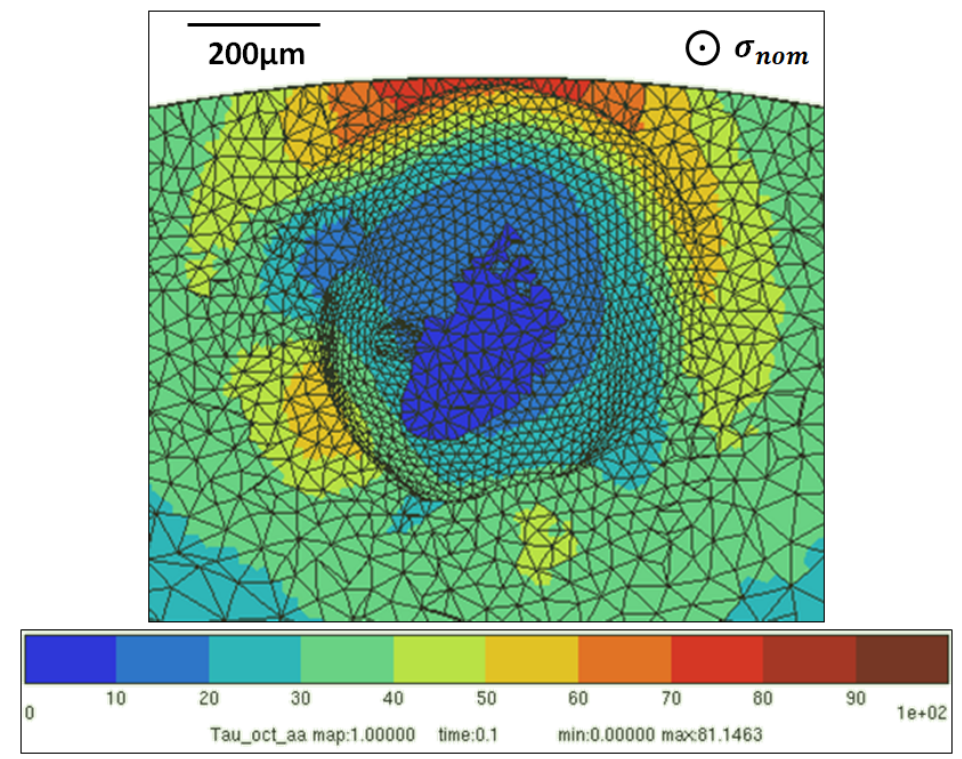

Figure 14: Spatial distribution of $\left\langle\tau_{o c t, a}\right\rangle$ for Critical defect \#1 positioned at $d=410 \mu \mathrm{m}$ from the surface. 
\#2. One can see that the two defects have the same criticality, the two distributions being tangent to

the threshold line. Such a result was expected, since each average defect was subjected to a loading that reproduces its average fatigue resistance. This result therefore supports the assumption that the Crossland parameter $\alpha$ of the present material is close to the slope $A$ of the threshold line. One can also note the differences between the two distributions, with higher shear stresses $\left\langle\tau_{o c t, a}\right\rangle$ for defect \#1 compared to defect \#2 resulting from the thin bridge of Average defect \#1.

The stress distributions of Average defect \#1 was then compared to that of Critical defect \#1 (Figure 15b). One can see that the critical defect has almost the same criticality as the average defect. It is interesting to note that this result is consistent regarding the fatigue life of Specimen 1, which was close to the $2 \times 10^{6}$ cycles for which the average fatigue resistance was assessed. A similar analysis can be made for Critical defect \#2. One can see in Figure $15 \mathrm{~b}$ that its criticality is much more important than that of the average defect, consistently with the fatigue life of Specimen 2 which was much less than $2 \times 10^{6}$ cycles.

Figure 16 compares the stress distributions related to internal defects and average subsurface defects, for both defects \#1 and \#2 (Figure 16a and Figure 16b respectively). One can see that the criticality is much more important for internal defects than for the subsurface ones. This result can be interpreted as follows. The experimental detection of a crack requires the crack to propagate over more than one millimeter. Given the significant size of the artificial defects, one may assume that this propagation stage is fast for the susbsurface defects, for which the propagation of the crack is assisted by the ambient air once the bridge of material is broken. In a first approximation, it is therefore possible to consider that the fatigue resistance obtained experimentally coincides with the fatigue resistance associated to the development of a crack over the first microstructural barriers, to which corresponds the application of the fatigue criterion. However, the observation of the fracture surfaces suggested that the growth of a crack initiated on an internal defect is much slower than for an external crack initiated on a subsurface defect, as mentioned in section 3.1.2. It is therefore possible that the propagation stage represents a non-negligible part of the fatigue lives for internal defect specimens, resulting in experimental fatigue resistances higher than the fatigue resistances associated with the development of a crack over the first microstructural barriers. Based on this assumption, 


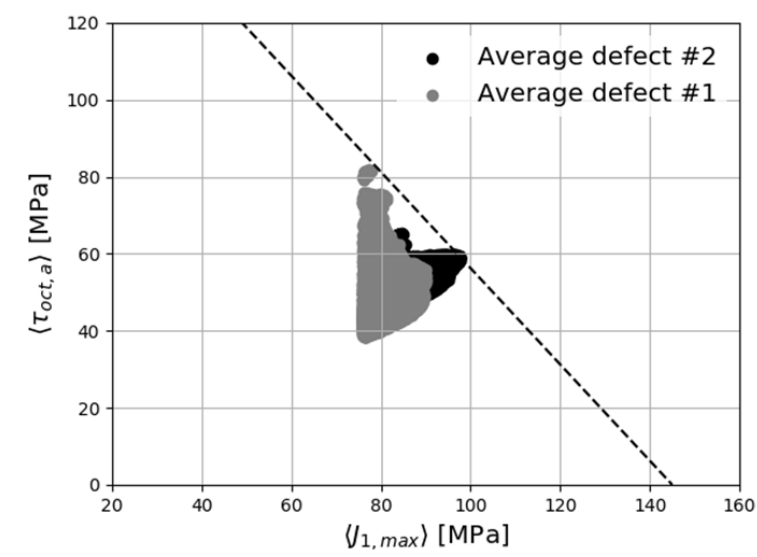

(a) Comparison of Average defects \#1 and \#2

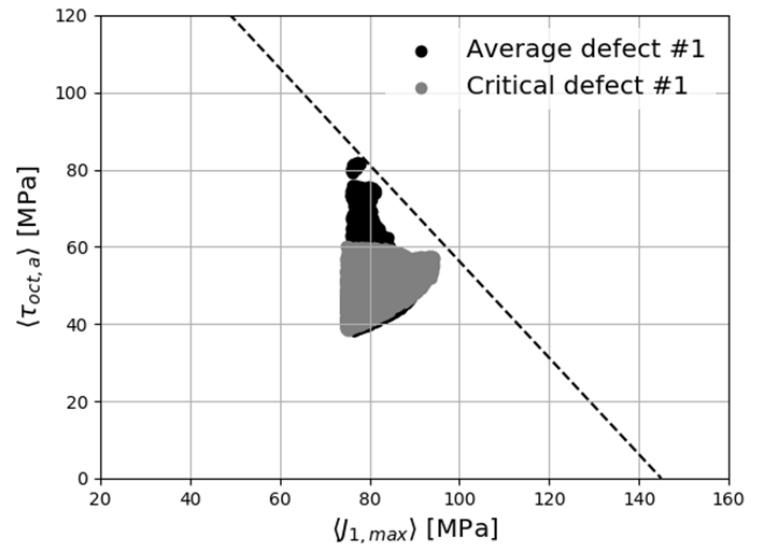

(b) Comparison of Critical defect \#1 and Average defect \#1

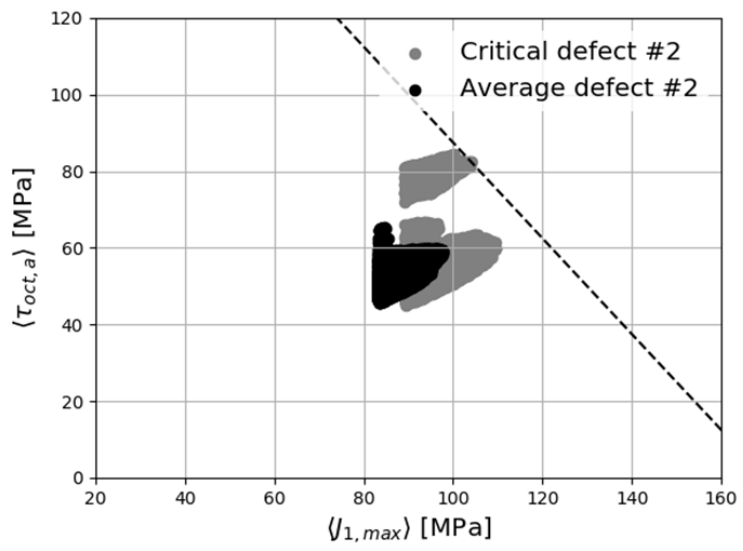

(c) Comparison of Critical defect \#2 and Average defect \#2

Figure 15: Comparison of the averaged stress distributions related to subsurface artificial defects

it comes natural that the criticalities of internal defects in terms of crack initiation are higher than those of the subsurface defects when the simulated defects are subjected to loadings reproducing the experimental fatigue resistances.

\section{Conclusion}

The results of this work can be summarized as follows:

1. It is possible to generate artificial defects of controlled sizes and positions in SLMed Al-Si alloys by introducing holes in the CAD files. 


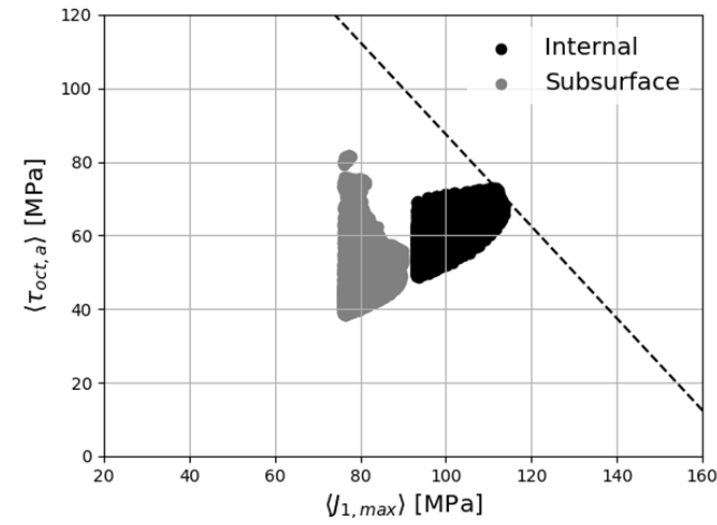

(a) Defect \#1

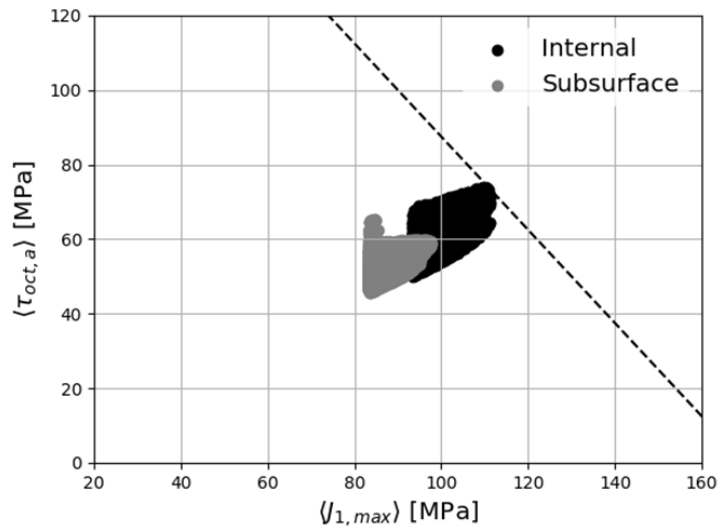

(b) Defect \#2

Figure 16: Comparison of the averaged stress distributions related to internal and subsurface average defects loaded with their respective experimental fatigue resistances (see Table 4)

2. Fatigue tests conducted on specimens with artificial defects exhibited an influence of defect position on the fatigue resistance. In particular, the results highlighted the great sensitivity of the fatigue resistance to the thickness of the bridge of material between the defect and the specimen surface for the case of subsurface defects.

3. A finite element analysis was conducted accounting for the real geometries of artificial defects. The results confirmed that the stress fields in the defect vicinity are greatly affected by the defect position. The criticalities of the different simulated defects, which were evaluated on the basis of a non-local Crossland criterion, were consistent with the experimental results. In particular, the different subsurface defect categories investigated in this study were found to have the same criticality when subjected to loadings reproducing their respective fatigue resistance.

4. When subjected to the experimental fatigue resistance, the criticalities of the simulated defects were higher for internal defects than for subsurface defects. This result suggested that the propagation stage before the experimental detection of a crack represents a non-negligible part of the fatigue life for the case of internal defects, unlike for the external cracks initiated on the subsurface defects for which the propagation is assisted by the environment. Such a statement was corroborated by the observations of the fracture surfaces that indicated different propagation mechanisms between the cracks initiated 
on the internal defects and those initiated on the subsurface defects.

\section{Acknowledgments}

IRT Saint Exupery, supported by Occitanie Region and industrial partners. In addition, the specimens were produced on the additive manufacturing platform of I2M institute Futurprod.

\section{References}

[1] E. Olakanmi, R. Cochrane, K. Dalgarno, A review on selective laser sintering/melting (SLS/SLM) of aluminium alloy powders: Processing, microstructure, and properties, Progress in Materials Science 74 (2015) 401-477. doi:10.1016/j. pmatsci.2015.03.002.

[2] S. Siddique, M. Imran, F. Walther, Very high cycle fatigue and fatigue crack propagation behavior of selective laser melted AlSi12 alloy, International Journal of Fatigue 94 (2017) 246-254. doi:10.1016/j.ijfatigue.2016.06.003.

[3] K. Yang, P. Rometsch, T. Jarvis, J. Rao, S. Cao, C. Davies, X. Wu, Porosity formation mechanisms and fatigue response in Al-Si-Mg alloys made by selective laser melting, Materials Science and Engineering: A 712 (2018) 166-174. doi: $10.1016 / \mathrm{j} \cdot \mathrm{msea} \cdot 2017.11 .078$.

[4] S. Romano, A. Brückner-Foit, A. Brandão, J. Gumpinger, T. Ghidini, S. Beretta, Fatigue properties of AlSi10mg obtained by additive manufacturing: Defect-based modelling and prediction of fatigue strength, Engineering Fracture Mechanics 187 (2018) 165-189. doi:10.1016/j.engfracmech.2017.11.002.

[5] Y. Murakami, Metal Fatigue: Effects of Small Defects and Nonmetallic Inclusions, elsevier Edition, 2002.

[6] T. Kitagawa, Applicability of fracture mechanics to very small cracks, ASM Proceedings of 2nd international conference on mechanical Metalspark (1976) 627-631.

[7] M. El Haddad, T. Topper, K. Smith, Prediction of non propagating cracks, Engineering Fracture Mechanics 11 (3) (1979) 573-584. doi:10.1016/0013-7944(79)90081-X.

[8] V. Le, Etude de l'influence des hétérogénéités microstructurales sur la tenue en fatigue à grand nombre de cycles des alliages d'aluminium de fonderie, Ph.D. thesis, Ecole Nationale Supérieure des Arts et Métiers (2016).

[9] K. J. Miller, The Short Crack Problem, Fatigue \& Fracture of Engineering Materials and Structures 5 (3) (1982) $223-232$. doi:10.1111/j.1460-2695.1982.tb01250.x.

[10] L. Susmel, The theory of critical distances: a review of its applications in fatigue, Engineering Fracture Mechanics 75 (7) (2008) 1706-1724. doi:10.1016/j.engfracmech.2006.12.004. 
[11] D. Taylor, Geometrical effects in fatigue: a unifying theoretical model, International Journal of Fatigue 21 (5) (1999) 413-420. doi:10.1016/S0142-1123(99)00007-9.

[12] D. Taylor, Prediction of fatigue failure location on a component using a critical distance method, International Journal of Fatigue 22 (9) (2000) 735-742. doi:10.1016/S0142-1123(00)00062-1.

[13] M. El May, N. Saintier, T. Palin-Luc, O. Devos, Non-local high cycle fatigue strength criterion for metallic materials with corrosion defects, Fatigue \& Fracture of Engineering Materials \& Structures 38 (9) (2015) 1017-1025. doi:10.1111/ffe. 12329.

[14] Y. Nadot, T. Billaudeau, Multiaxial fatigue limit criterion for defective materials, Engineering Fracture Mechanics 73 (1) (2006) 112-133. doi:10.1016/j.engfracmech.2005.06.005

[15] B. Vayssette, N. Saintier, C. Brugger, M. El-May, E. Pessard, Numerical modelling of surface roughness effect on the fatigue behavior of Ti-6al-4v obtained by additive manufacturing, International Journal of Fatigue 123 (2019) $180-195$. doi:10.1016/j.ijfatigue.2019.02.014.

[16] S. Siddique, M. Imran, M. Rauer, M. Kaloudis, E. Wycisk, C. Emmelmann, F. Walther, Computed tomography for characterization of fatigue performance of selective laser melted parts, Materials \& Design 83 (2015) 661-669. doi: $10.1016 / j$. matdes . 2015.06.063

[17] A. Fatemi, R. Molaei, S. Sharifimehr, N. Phan, N. Shamsaei, Multiaxial fatigue behavior of wrought and additive manufactured Ti-6al-4v including surface finish effect, International Journal of Fatigue 100 (2017) 347-366. doi: 10.1016/j.ijfatigue.2017.03.044.

[18] A. Borbély, H. Mughrabi, G. Eisenmeier, H. Höppel, A finite element modelling study of strain localization in the vicinity of near-surface cavities as a cause of subsurface fatigue crack initiation, International Journal of Fracture 115 (2002) 227-232.

[19] Y. Gao, J. Yi, P. Lee, T. Lindley, The effect of porosity on the fatigue life of cast aluminium-silicon alloys, Fatigue \& Fracture of Engineering Materials and Structures 27 (7) (2004) 559-570. doi:10.1111/j.1460-2695.2004.00780.x.

[20] I. Serrano-Munoz, Influence of casting defects on the fatigue behaviour of an A357-T6 aerospace alloy, Ph.D. thesis, Institut National des Sciences Appliquées de Lyon (2014)

[21] I. Serrano-Munoz, J.-Y. Buffiere, C. Verdu, Y. Gaillard, P. Mu, Y. Nadot, Influence of surface and internal casting defects on the fatigue behaviour of A357-T6 cast aluminium alloy, International Journal of Fatigue 82 (2016) 361-370. doi:10.1016/j.ijfatigue.2015.07.032.

[22] G. Henaff, G. Odemer, A. Tonneau-Morel, Environmentally-assisted fatigue crack growth mechanisms in advanced materials for aerospace applications, International Journal of Fatigue 29 (9-11) (2007) 1927-1940. doi:10.1016/j.ijfatigue. 2007.03 .014$.

[23] S. Romano, A. Brandão, J. Gumpinger, M. Gschweitl, S. Beretta, Qualification of AM parts: Extreme value statistics applied to tomographic measurements, Materials \& Design 131 (2017) 32-48. doi:10.1016/j.matdes.2017.05.091. 
[24] Y. Murakami, M. Endo, Quantitative evaluation of fatigue strength of metals containing various small defects or cracks, Engineering Fracture Mechanics 17 (1) (1983) 1-15. doi:10.1016/0013-7944(83)90018-8.

[25] J.-Y. Buffière, S. Savelli, P. Jouneau, E. Maire, R. Fougères, Experimental study of porosity and its relation to fatigue mechanisms of model Al-Si7-Mg0.3 cast Al alloys, Materials Science and Engineering: A 316 (1-2) (2001) 115-126. doi:10.1016/S0921-5093(01)01225-4.

[26] P. J. Armstrong, C. O. Frederick, A mathematical representation of the multiaxial Bauschinger effect, Tech. Rep. Central Electricity Generating Board Report RD/B/N731, Berkeley Nuclear Laboratories, Research \& Development Dept. (1966).

[27] B. Crossland, Effect of large hydrostatic pressures on the torsional fatigue strength of fan alloy steel, in: Proceedings of the international conference on fatigue of metals, London and New York, 1956, pp. 138-149.

[28] S. Romano, A. Abel, J. Gumpinger, A. Brandão, S. Beretta, Quality control of AlSi10mg produced by SLM: Metallography versus CT scans for critical defect size assessment, Additive Manufacturing 28 (2019) 394-405. doi:10.1016/j.addma. 2019.05 .017

[29] P. Mu, Y. Nadot, C. Nadot-Martin, A. Chabod, I. Serrano-Munoz, C. Verdu, Influence of casting defects on the fatigue behavior of cast aluminum AS7g06-T6, International Journal of Fatigue 63 (2014) 97-109. doi:10.1016/j.ijfatigue. 2014.01 .011

[30] P. Mu, Y. Nadot, I. Serrano-Munoz, A. Chabod, Multiaxial fatigue design of cast parts: Influence of complex defect on cast AS7g06-T6, Engineering Fracture Mechanics 131 (2014) 315-328. doi:10.1016/j.engfracmech.2014.08.007. 